\title{
Toward Healthy Cities. People, Places, the Politics of Urban Planning and Power
}

\section{Jason Corburn, Published and Available from the Massachusetts Institute of Technology (MIT) Press, 55 Hayward Street, Cambridge, MA 02142, 2009, 282 pages, ISBN 978-0-262-51307-4, http://mitpress.mit.edu}

\section{Francoise Barten}

Toward the Healthy City by Jason Coburn offers an interesting journey through the history of planning and public health in the United States, by examining the common ground of health and social justice, as well as the forces and circumstances responsible for the disconnect between the fields during the 20th century. The book provides concrete evidence for the need to reconnect the fields to address the systemic failure and health crises in today's cities. The author suggests a new decision-making framework and explores how public health and planning agencies along with community-based coalitions in the San Francisco Bay Area are currently redefining environmental health policies to improve the health of both people and places. The book herewith moves beyond much contemporary research that tends to document problems in cities, and in particular in poor neighborhoods and communities, without examining the political and administrative changes in municipal government and governance.

Chapter 1 is introductory and explains the challenges for "healthy city planning." The starting point is the understanding of urban places and city planning processes as critical determinants of population health. The author explains that recent efforts to reconnect the fields of public health and urban planning in the United States have focused on a very limited conception of healthy planning, and suggests a new and more comprehensive decision-making framework: "healthy city planning." Chapter 2 critically reviews the practices of US city planning and public health from the late 19 th century to the start of the 21st century. Chapter 3 then considers how city planning processes fail to address the social determinants of health and contribute to the perpetuation of health inequity in cities. Chapter 4 specifically considers alternative issue framings that include considerations of population health, a relational view of place, processes of governance, and relations of power. The author applies this conceptual framework in the analysis of three case studies (2004-2008) of healthy city planning in San Francisco and across the Bay Area: the reframing of environmental health practice, healthy urban development, and using health impact assessment for urban and regional planning. These cases, described in chapters 5-7, clearly illustrate how planning can return to its health and

\footnotetext{
Barten is with the Ministerio de Salud, El Salvador (MINSAL), San Salvador, El Salvador.

Correspondence: Francoise Barten, Radboud University Nijmegen Medical Centre, Department Primary and Community Care, Nijmegen Urban Health Group, Nijmegen, the Netherlands. (E-mail: f.barten@elg.umcn.nl)
} 
social justice roots and what new political processes can help reconnect planning and public health to address the social determinants of health inequities in cities. Finally, the author draws some lessons to be learned and ends the book with some recommendations.

These lessons learned are not only of interest to urban planners, public health professionals, and community members in the United States, but also to practitioners in cities worldwide. Throughout the book, the author seeks to explain that making physical changes to places, without accompanying political and institutional change at different levels, will ultimately fail to improve the health of disadvantaged urban populations and to develop more healthy and equitable cities. Governance practices and power need to be examined. Considering the advent of new and powerful actors in the urban arena, the differing existing governance arrangements and agendas within the same city, the struggles over power as well as the impact of external forces on local development and processes, this recommendation appears to be very relevant.

This book addresses urban politics at neighborhood, city, and regional levels, but does not examine the impact of economic globalization, the financial crisis, the increasing inequities between cities, and therefore the need to address governance issues and policy making at the national and/or global level. If the health sector-as suggested by the author-should play a leadership role, then the nature of health care reform and the brain drain of human resources matter as well. Also, the contradictory role of municipal governments in an increasingly globalized world needs further scrutiny. Considering the impact of global challenges like the financial crisis, the expected impact of climate change, and food insecurity on healthy city planning, it would be of interest to build upon and further develop the policy framework proposed by Jason Corburn.

OPEN ACCESS This article is distributed under the terms of the Creative Commons Attribution Noncommercial License which permits any noncommercial use, distribution, and reproduction in any medium, provided the original author(s) and source are credited. 